\title{
Correlation between strain rate sensitivity and characteristics of Portevin- LeChátelier bands in a twinning-induced plasticity steel
}

\author{
Xiangde Bian ${ }^{\mathrm{a}, \mathrm{b}}$, Fuping Yuan ${ }^{\mathrm{a}, \mathrm{b}, *}$, Xiaolei $\mathrm{Wu}^{\mathrm{a}, \mathrm{b}}$ \\ a State Key Laboratory of Nonlinear Mechanics, Institute of Mechanics, Chinese Academy of Sciences, No.15 Beisihuanxi Road, Beijing 100190, China \\ b School of Engineering Scence, University of Chinese Academy of Sciences, No.19(A) Yuquan Road, Beijing 100049, China
}

\section{A R T I C L E I N F O}

\section{Keywords:}

TWIP steels

Dynamic strain aging

Portevin-LeChátelier bands

Strain rate sensitivity

Serrated flow behaviors

Digital image correlation

\begin{abstract}
A B S T R A C T
The effects of strain rates on the deformation behaviors of a twinning-induced plasticity (TWIP) steel (Fe23Mn0.6 C) have been investigated using uniaxial continuous tensile tests at different strain rates and strain-rate jump tests, coupled with digital image correlation (DIC) method. A positive instantaneous strain rate sensitivity (ISRS), a negative strain rate sensitivity of work hardening (SRSW) and a negative overall strain rate sensitivity (SRS) have been revealed in the present TWIP steel. The critical strain for appearance of PortevinLeChátelier (PLC) bands increases while the height of serrated flow behaviors decreases with increasing strain rate, which indicates that the dynamic strain aging (DSA) effect is suppressed at higher strain rates. The strain concentration in PLC bands is found to be more severe at higher strain rates. Moreover, the appearance/ disappearance of PLC band in strain-rate jump tests is found to be highly dependent on the deformation and microstructure evolution histories. Thus, the negative SRSW can be attributed to the higher strain concentration in the PLC bands and the restriction of DSA at higher strain rates, which are related to the suppression of deformation twins at higher strain rates.
\end{abstract}

\section{Introduction}

Twinning-induced plasticity (TWIP) steels have been one of most promising materials due to their superior mechanical properties with high strength, high ductility and high work hardening capacity [1-9]. The strong strain hardening rate for the coarse-grained (CG) TWIP steels have been attributed to the so called "dynamic Hall-Petch (DHP) effect", i.e., the reduction of the dislocation mean free path by deformation twins (DTs), which generally start to form in favorablyoriented grains after a few percent plastic deformation by slip [5-8]. Driven by the need of impact-tolerant structures in the automotive industry and military defense, the deformation behaviors of TWIP steels have been extensively investigated at awide range of strain rates and temperatures [10-14].

The strength at the yielding point for TWIP steels has been observed to generally increase with increasing strain rate, showing a strong positive strain rate sensitivity (SRS) for yielding strength $[15,16]$. Moreover, the sudden increase/decrease in the strain rate by the strain-rate jump tests also leads to a sudden increase/decrease in the flow stress, resulting in a positive instantaneous strain rate sensitivity (ISRS) for TWIP steels [16-21]. These phenomena have revealed the thermally-activated nature of dislocation nucleation and propagation in
TWIP steels, thus the SRS at a given microstructure and a given temperature, such as positive SRS at yielding, should be attributed to the increased resistance of the mobile dislocations with increasing strain rate [22].

However, the experiments conducted at different strain rates and the steady flow stress in the strain-rate jump tests have shown a negative overall SRS for TWIP steels [17-21,23]. On one hand, dynamic strain aging (DSA) has been proposed in the literature $[3,12,15,16]$ to be responsible for such negative overall SRS. In the presence of DSA, the strain localization such as Portevin-LeChátelier (PLC) band and the serrated flow behavior appear in TWIP steels $[3,16]$. PLC band and it effect on the mechanical properties of TWIP steels have attracted great interests for the past decade, and were investigated using infrared cameras [16,23-26], laser extensometers [27,28] and digital image correlation (DIC) [29-34]. The PLC bands in TWIP steels can be classified into three types (Types A, B and C) based on their dynamic appearance characters [33-36]. Type A bands usually propagate continuously across the whole tensile specimen, and the formation of type B bands is generally discontinuous but regularly, while type $\mathrm{C}$ bands usually appear randomly (discontinuously and in a non-correlated way).

On the other hand, the negative overall SRS has also been found in

\footnotetext{
* Corresponding author at: State Key Laboratory of Nonlinear Mechanics, Institute of Mechanics, Chinese Academy of Sciences, No.15 Beisihuanxi Road, Beijing 100190, China.

E-mail addresses: bianxiangde@imech.ac.cn (X. Bian), fpyuan@lnm.imech.ac.cn (F. Yuan), xlwu@imech.ac.cn (X. Wu).
} 
the plastic deformation of TWIP steels without DSA [18-21,37]. Thus, other mechanisms and deformation physics, instead of DSA, therefore should be responsible for the negative overall SRS in the DSA-free TWIP steels. According to the Klepaczko's work [38], the overall SRS can be divided into two parts, i.e., the ISRS that is a microstructure and temperature independent parameter and the strain rate sensitivity of work hardening (SRSW) that is highly dependent on the microstructure evolution. The negative SRSW in TWIP steels has been proposed to be attributed to the suppression of dislocations and DTs, which is caused by the adiabatic heating associated with the high strain rate deformation $[39,40]$.

Nevertheless, previous research have shown that the effects of strain rate on the deformation behaviors and the mechanical properties of TWIP steels are totally different from other conventional fcc metal and alloys $[13,15,41]$. The fundamental understandings on the negative overall SRS and the characteristics of PLC band are still required further study. For example, is there any correlation between the negative SRSW and the magnitude of strain concentration in the PLC band? How the deformation history or microstructure evolution history affects the appearance of PLC band in the strain-rate jump tests? In this regard, a series of uniaxial continuous tensile tests at various strain rates and strain-rate jump tests, coupled with in-situ strain mapping on sample surfaces using DIC, have been conducted in the present study to investigate these issues in a TWIP steel (Fe23Mn0.6C).

\section{Materials and experimental procedures}

The TWIP steel used in the present study has a chemical composition of $0.6 \mathrm{C}, 23 \mathrm{Mn}, 0.035 \mathrm{Nb}, 0.035 \mathrm{Ti}$, and the balance of Fe (all in wt $\%)$. Under the protection of Ar atmosphere, the TWIP steel was first melted in an induction furnace and then cast to ingots with a thickness of $170 \mathrm{~mm}$. The ingots were heat-treated at $1150{ }^{\circ} \mathrm{C}$ for $2 \mathrm{~h}$, and then hot-forged into slabs with a thickness of $20 \mathrm{~mm}$ between $1150{ }^{\circ} \mathrm{C}$ and $900{ }^{\circ} \mathrm{C}$. The slabs were annealed at $700{ }^{\circ} \mathrm{C}$ for $1 \mathrm{~h}$ and immediately quenched in water to obtain an austenite CG microstructure with an average grain size of about $15 \mu \mathrm{m}$ (Fig. 1). A few annealing twins are also found in the annealed CG structure, as marked by arrows in Fig. 1. The microstructures before and after tensile tests were revealed by Electron backscattered diffraction (EBSD). The samples for EBSD were grinded to 2000 grit first by sandpapers, and were then polished with a $0.05 \mu \mathrm{m} \mathrm{SiO}{ }_{2}$ aqueous solution, followed by electro-polishing with a solution of $10 \% \mathrm{HCLO}_{4}$ and $90 \%$ alcohol at $22 \mathrm{~V}$ and $-20{ }^{\circ} \mathrm{C}$. The phase information and texture evolution before and after tensile tests were obtained on polished surfaces by X-ray diffraction (XRD) measurements using a Philips Xpert X-ray diffractometer with $\mathrm{Cu}$ Ka radiation.

Dog-bone plate samples with a thickness of about $1 \mathrm{~mm}$ were used for the quasi-static uniaxial tensile tests. The dimensions of the gauge section are $13 \times 2.5 \mathrm{~mm}^{2}$. These continuous tensile tests were con-

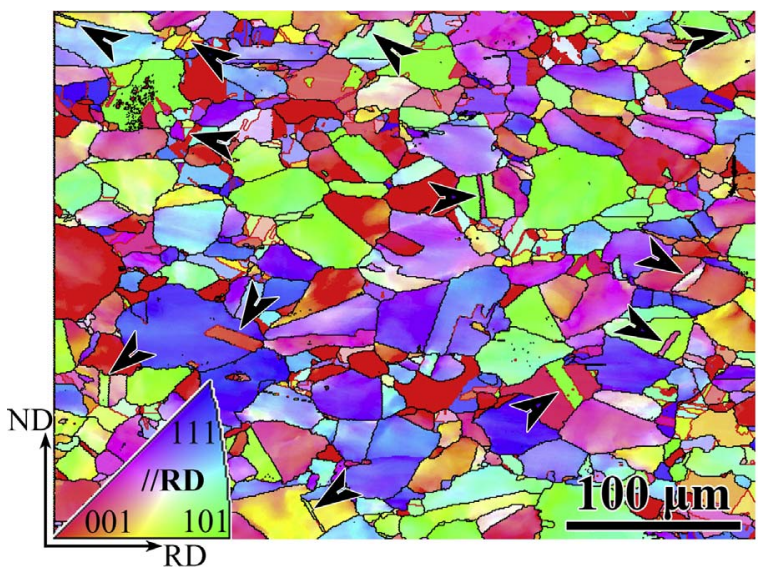

Fig. 1. EBSD (Inverse Pole Figure, IPF) image for the CG sample before tests. ducted at room temperature by displacement control using an Instron 5582 universal testing machine under various strain rates $\left(3.8 \times 10^{-4}\right.$, $\left.2.5 \times 10^{-3}, 1.3 \times 10^{-2}, 1.3 \times 10^{-1} / \mathrm{s}\right)$. At least two experiments were conducted for each strain rate to check the repeatability. Strain-rate jump tests with both upward and downward strain rate changes were also conducted at room temperature (two strain-rate jump experiments were also provided to check the repeatability). The flow behaviors in strain-rate jump tests can be characterized by an instantaneous response followed by a steady-state behavior. The ISRS and the SRS for steady state were then evaluated using a short back-extrapolation method [3]. During the continuous tensile tests and the strain-rate jump tests, the contours of strain rate and strain were measured by DIC, and the data was analyzed by the commercial software ARAMIS ${ }^{\circ}$. Initial high-contrast stochastic patterns of spots, in which a fine layer of black paint spots (with size of about $10 \mu \mathrm{m}$ ) was sprayed on a background with a thin layer of white adhesive paint, were constructed on the polished sample surfaces. The measured first image represents the undeformed state, and the subsequent images for the evolution of the spotted patterns were recorded using a 1.2 MPx digital CCD camera at a rate of 1 frame per second. A facet size of $110 \mu \mathrm{m}$ was used for the strain calculation using DIC method.

\section{Results and discussions}

First, uniaxial continuous tensile tests at different strain rates were conducted, and the engineering stress-strain curves are shown in Fig. 2a. The corresponding true stress-strain curves are displayed in Fig. 2b. In the inset of Fig. 2b, we show the good repeatability for the tensile experiments by displaying two experiments conducted at strain rate of $3.8 \times 10^{-4} / \mathrm{s}$. It is shown that the flow stress at small strain range $(<15 \%)$ increases with increasing nominal strain rate, while the flow stress at large strain range $(>20 \%)$ decreases with increasing nominal strain rate. The flow stress differences for different strain rates increases with increasing applied true strain at large strain range $(>20 \%$ ), and this indicates that the work hardening capability is higher at lower strain rate. The yielding strength $\left(\sigma_{0.2}\right)$, the ultimate strength and the uniform elongation are plotted as a function of the nominal strain rate in Fig. 2c. As indicated, the yielding strength increases while both the ultimate strength and the uniform elongation decrease with increasing nominal strain rate.

The SRS in the continuous tensile tests can be defined as the following equation at a given temperature and a given strain:

$m=\left(\frac{\partial \ln \sigma}{\partial \ln \dot{\varepsilon}}\right)_{\varepsilon, T}$

Thus, the SRS for yielding strength and the SRS for the flow stress at a true strain of $45 \%$ are calculated and are plotted as a function of the nominal strain rate in Fig. 2d. As shown, this TWIP steel shows a positive SRS for the yielding strength while a negative SRS for the flow stress at large strain. At the yield point, the temperature and the microstructure should be the same for the experiments conducted at various strain rates. Thus, this positive SRS at yielding point should be attributed to the thermally-activated nature of dislocation nucleation and propagation in this TWIP steel, i.e., the resistance of the mobile dislocations increases with increasing strain rate [17-21]. While the SRS for the flow stress at large strain should be highly dependent on the microstructure evolution and the characteristics of PLC band, and the detailed analysis will be provided in the following sections.

Serrated flow behaviors are observed for all experiments conducted at various strain rates, as shown in Fig. 2b. These serrated flow behaviors can be attributed to the DSA effect $[3,35,42]$. The serration behaviors generally start at a critical applied strain with a fine and short shape, which indicates that DSA usually does not occur immediately after the start of straining. This is proposed to be due to the fact that sufficient vacancies must be created first during tension to facilitate the 

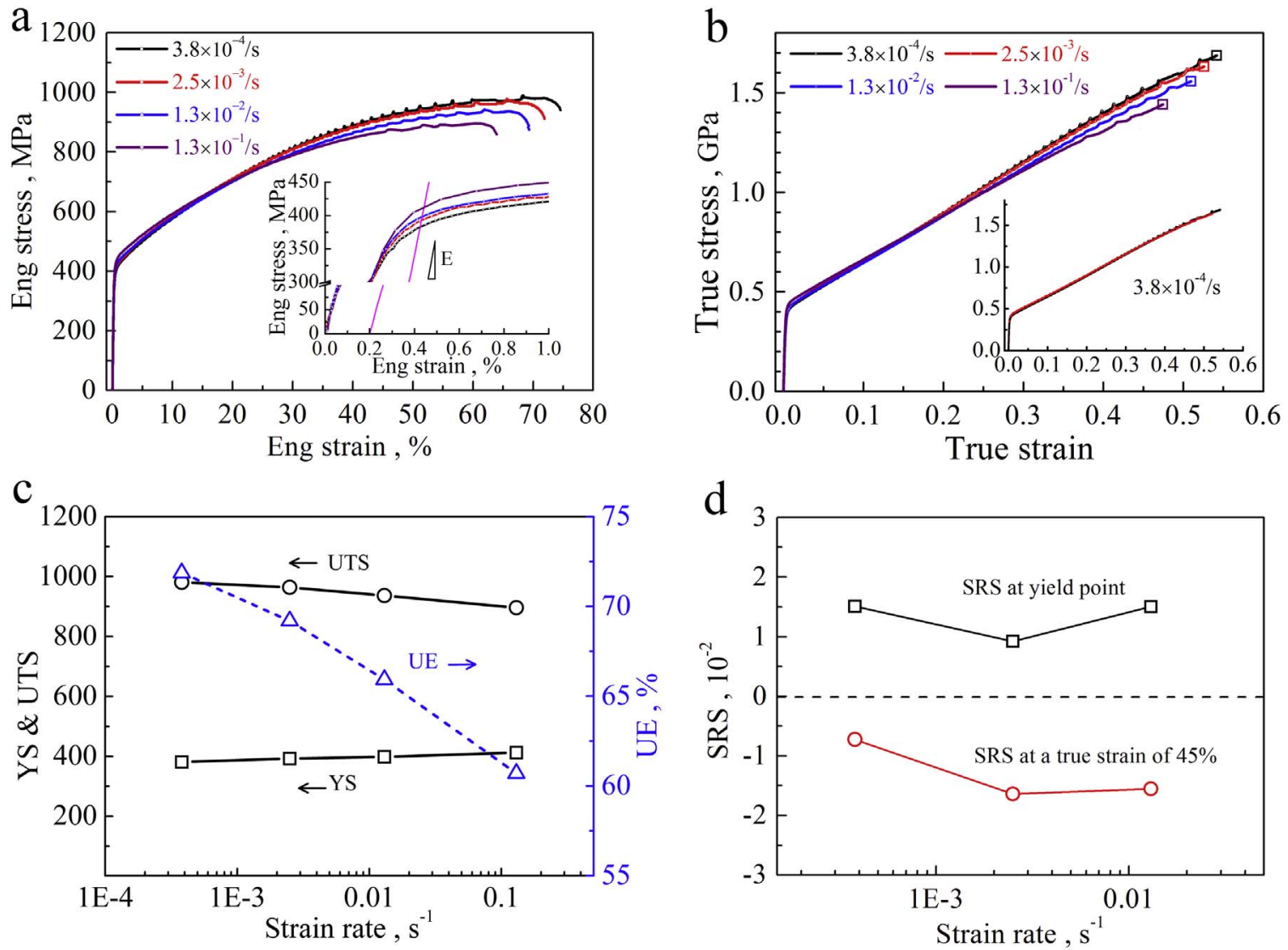

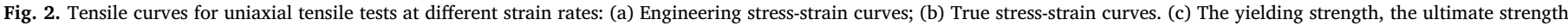

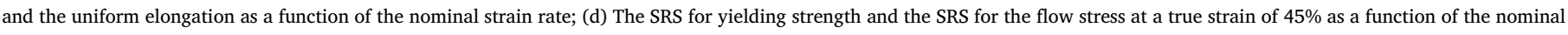
strain rate.
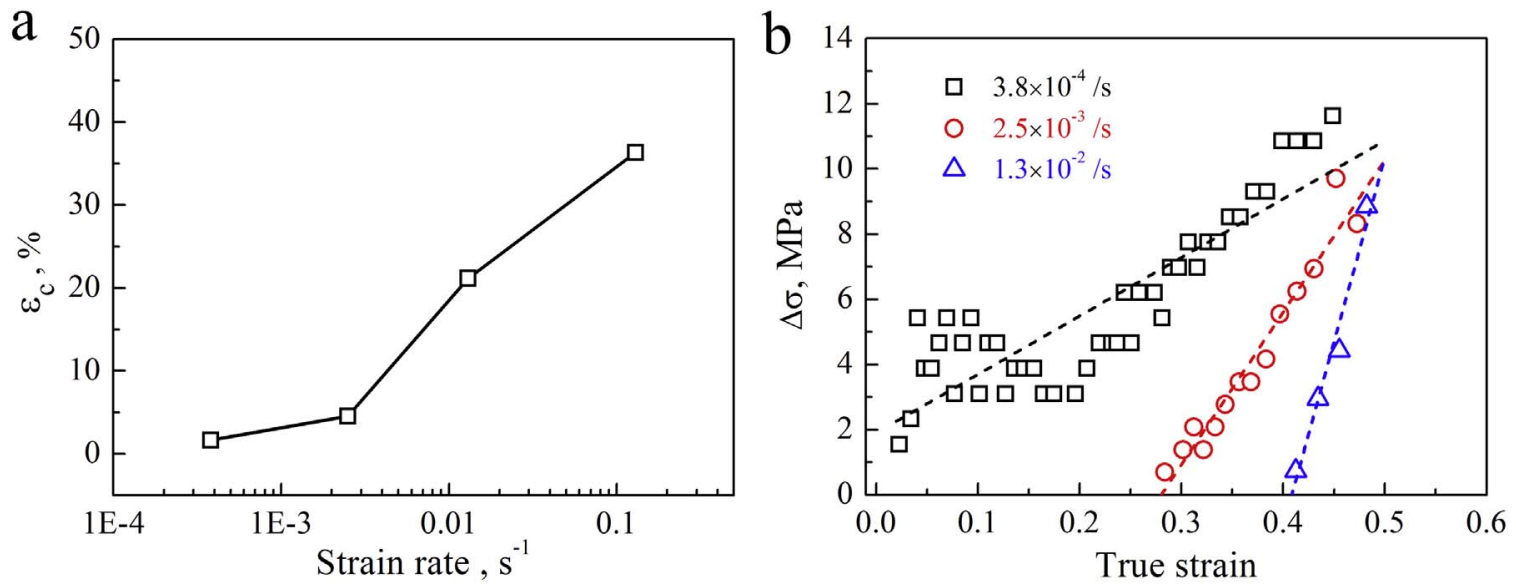

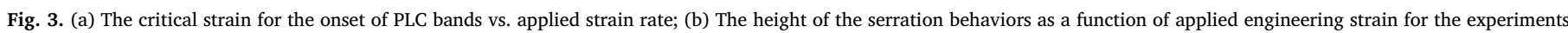
conducted at three different strain rates. The dash lines in Fig. $3 \mathrm{~b}$ are the linear fitting curves for the experimental data.

solute diffusion to dislocations for DSA [43]. The height and the interval of the serration behaviors increase with increasing applied strain for each experiment. Each serration on the flow curves should correspond to the nucleation and the propagation of one PLC band, which will be discussed in details later. Interestingly, the critical strain for the onset of serrated behaviors/PLC bands is observed to increase with increasing strain rate (Fig. 3a), and the height of the serration behaviors is lower at higher strain rate (Fig. 3b). These observations indicate that DSA effect is suppressed in this TWIP steel with increasing strain rate, and the corresponding mechanism and the microstructure evolution effect on the DSA will also be discussed in details later.

Based on DIC data, distribution of strain rate along the tensile direction ( $\mathrm{x}$ ) as a function of time for the experiment conducted at strain rate of $3.8 \times 10^{-4} / \mathrm{s}$ is illustrated in Fig. 4a. The corresponding load curve as a function of time is also plotted in Fig. $4 \mathrm{~b}$ to correlate the nucleation and the propagation of PLC bands with the serrated flow behaviors. In Fig. 4a, the red and yellow colors, representing the peak strain rates which are one order higher than the nominal applied strain rate, are associated with the localized deformations, i.e., PLC bands. Before $120 \mathrm{~s}$, the strain rate for the whole gage section is almost uniform (with homogeneous blue or light blue color), which indicates no PLC effect and no serration flow behaviors before $120 \mathrm{~s}$. After $120 \mathrm{~s}$, the first band nucleates from the middle of the gage section, while the following bands all nucleate from the bottom end of the gage section. 


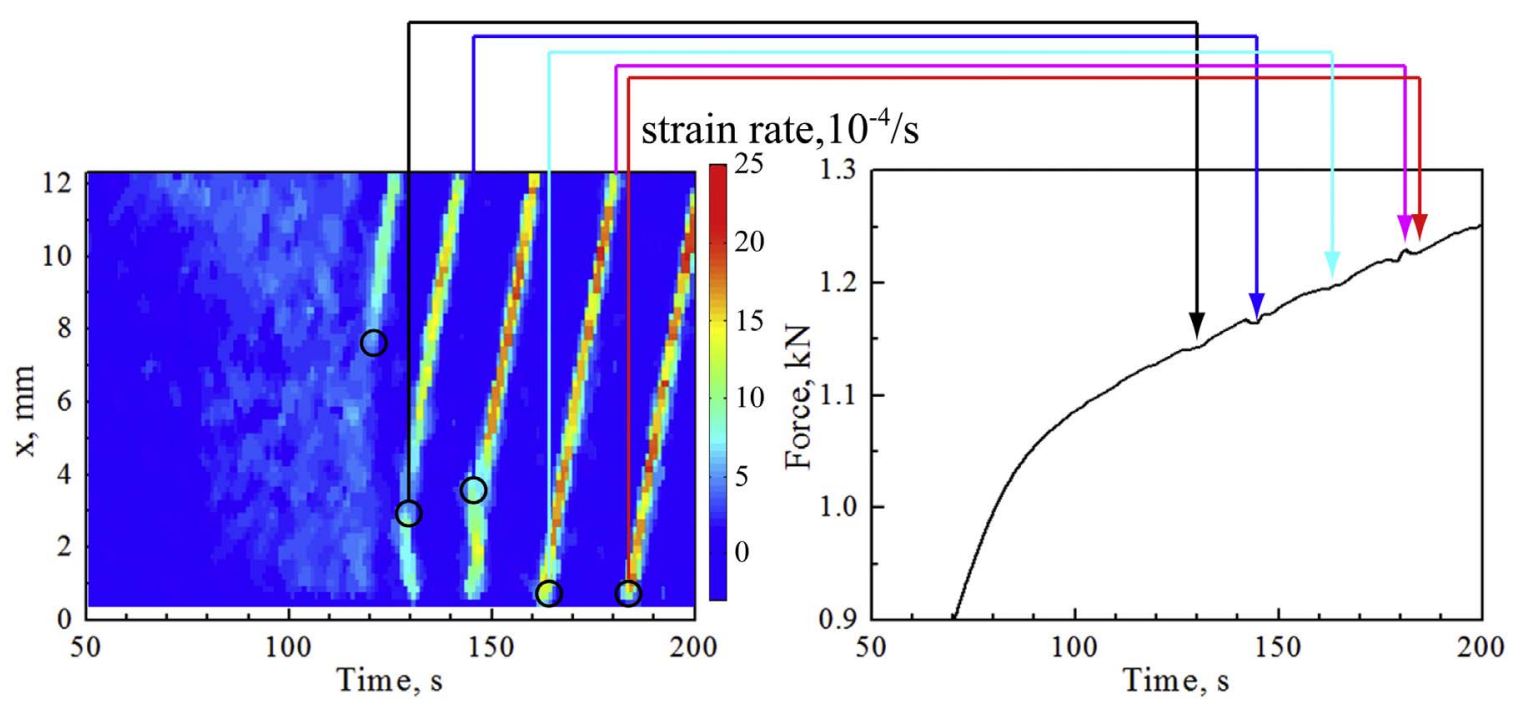

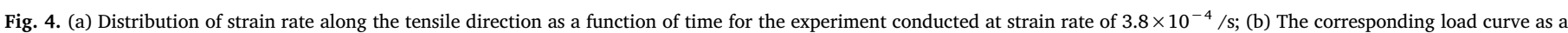
function of time.

The PLC bands are observed to always propagate continuously in the same direction to the top end, thus this kind of PLC bands can be identified as Type-A according to the previous research $[35,36]$. The nucleation of each PLC band is corresponding to a load drop in Fig. 4b, while the load gradually increases during the propagation process of each PLC band. Once the PLC band dies away from the top end of the gage section, the load can suddenly rise before the nucleation of next PLC band.

Based on the evolution of the strain rate contour (Fig. 4a), the apparent propagation velocity of the PLC band at current time can be defined as:

$v_{B}=\delta / \Delta t$

where $\delta$ is the propagation distance of the PLC band at the time interval of $\Delta t$.

The evolutions of band velocities with applied strain are shown in Fig. 5a for experiments conducted at various strain rates. It is observed that the band velocities decrease with increasing applied strain, and the final fracture occurs when the propagation of the PLC band is suppressed and the band velocities approach zero. During the propagation of each PLC band, the strain rate within the PLC band is one order higher than that outside the band, thus the nominal strain increment of the whole specimen should be concentrated in the PLC band, and the strain increment outside the band should be negligible during the propagation process. Once the propagation of the PLC band is suppressed to almost zero velocity, the strain concentration will occur at a fixed location, resulting in necking and final fracture. It is shown that a higher band velocity is observed for a higher nominal strain rate because the crosshead velocity is higher at higher nominal strain rate. The normalized band velocity by the crosshead velocity, however, is shown to be lower for higher nominal strain rate (Fig. 5b). The strain within the PLC band can be estimated as [3]:

$\Delta \varepsilon_{B}=v_{C} / v_{B}$

where $v_{C}$ is the crosshead velocity.

Thus, the evolutions of strain within the PLC band with applied strain are shown in Fig. $5 \mathrm{c}$ for experiments conducted at various strain rates. It is observed that the strain concentration within PLC band is more severe when the nominal strain rate is higher. This higher strain concentration in the deformation band generally indicates a lower strain hardening capability for metals and alloys [44]. For example, the strain is more easily to concentrate and the plastic instability such as necking is more prone to occur in the nanostructured metals due to their low strain hardening ability when compared to the CG counterpart
[44]. Thus, the negative of SRSW can be attributed to the higher strain concentration in the PLC bands at higher strain rates, and this higher strain concentration can be related to the microstructure evolution in the TWIP steel under tension and this effect will be discussed next.

The restriction of DSA effect and the more severe strain concentration in the PLC bands at higher strain rates should be highly dependent on the microstructure evolutions under uniaxial tensile deformation at various strain rates. The microstructures measured by EBSD for the experiments conducted at different strain rates $\left(2.5 \times 10^{-3}, 1.3 \times 10^{-2}\right.$, $1.3 \times 10^{-1} / \mathrm{s}$ ) are displayed in Figs. $6 \mathrm{a} 1-6 \mathrm{c} 1$ (at the strain of $20 \%$ for each strain rate) and Figs. $6 a 2-6 c 2$ (at the strain of the uniform elongation for each strain rate). The blue lines in the Figs. $6 a 1-6 c 1$ and Figs. $6 \mathrm{a} 2-6 \mathrm{c} 2$ are related to the DTs. The corresponding texture intensity maps for Figs. 6a2-6c2 are shown in Figs. 6a3-6c3. As shown, the texture of Brass $\{110\}<112>$ (related to DTs [14],) decreases with increasing strain rates, which is consistent with the EBSD maps. It is shown that the density of DTs decreases with increasing strain rate, which is consistent with previous work $[14,15]$. It is proposed that the twinning propensity at different strain rates should be highly related to the characteristics of PLC bands and the DSA effect. It should be noted that the strain rate within PLC band is one order higher than the applied strain rate, thus an adiabatic temperature rise of about $100{ }^{\circ} \mathrm{C}$ for the experiment with highest strain rate should exist $[1,16]$, thus the DTs may be suppressed due to this adiabatic heating at higher strain rates.

The previous investigations have also shown that DSA effect has a significant effect on the twinning propensity of FeMnC steels [15]. The possible mechanisms are provided as following. As we know, when the leading partial dislocation passes a perfect fcc lattice structure, a local hcp structure is formed in the stacking faults (SFs). Due to this local crystal structure change, the position of $\mathrm{C}$ atoms may transfer from octahedral to tetrahedral sites. While the $\mathrm{C}$ atoms should readily jump back to the octahedral sites since the tetrahedral sites are not stable. These "jump back" C atoms may lock the motion of the trailing partial dislocations [15]. Thus, DSA can be attributed to the reorientation of Cvacancy complexes in the stress field of extended dislocations, and the DSA effect can only occur when the reposition time of $C$ atoms is less than the waiting time for locking [15]. The distance between the leading partial dislocations and the trailing partial dislocations, i.e. the width of SFs between them should increase when the trailing partial dislocations are locked by $\mathrm{C}$ atoms. Thus, the nucleation and the propagation of DTs can be facilitated by the increase of the SF width due to the DSA effect. Fig. 3 already shows that the DSA effect is suppressed with increasing strain rates, which can restrict the formation and the propagation of DTs at higher strain rates (Fig. 6). This is 

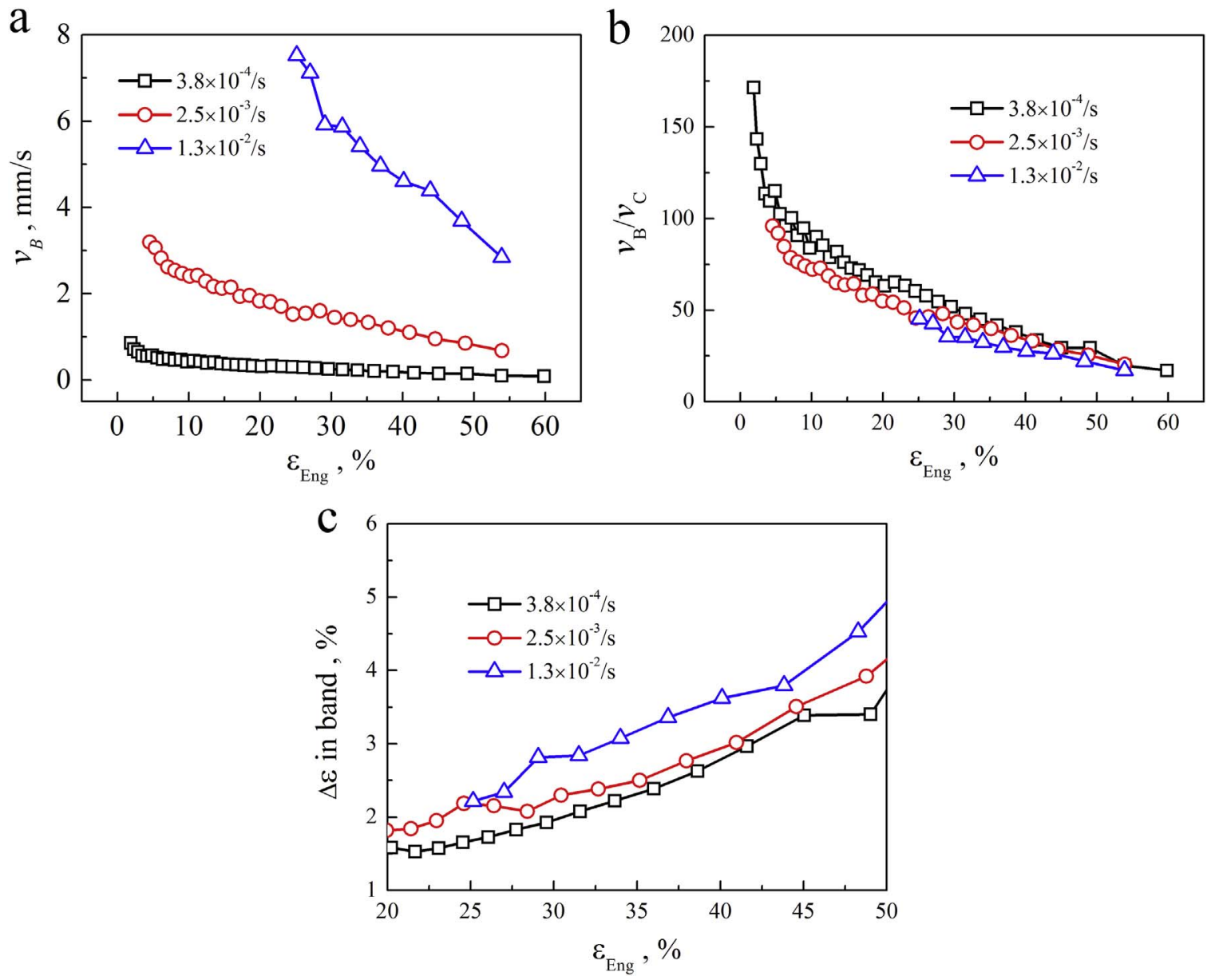

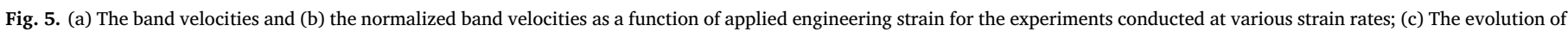
strain within the PLC band with applied engineering strain for the experiments conducted at various strain rates.

because the waiting time for locking is reduced at higher strain rates, which restricts the DSA effect. As a summary, the suppression of DTs at higher strain rates can be attributed to the adiabatic heating in the more severely concentrated PLC bands and the restriction of DSA effect by the reduced time for locking with increasing strain rate.

Strain rate jump tests were also conducted at room temperature. Both upward and downward jump tests at strain rate range from $3.8 \times 10^{-4}$ to $1.3 \times 10^{-2} / \mathrm{s}$ were conducted to obtain the SRS as a function of applied strain. Fig. 7a shows the true stress vs. true strain curve for the strain rate jump tests. In Fig. 7a, one inset shows how to calculate the instantaneous stress and the steady-state stress based on a short back-extrapolation method [3], while the other inset shows the good repeatability for strain rate jump tests by displaying two curves conducted at the same loading conditions. As observed, the sudden increase/decrease in the strain rate leads to a sudden increase/decrease in the true stress, and then the true stress gradually decreases/increases to a steady-state level lower/higher than the true flow stress prior to the strain rate change, due to the negative nature of SRSW. The ISRS, the steady-state strain rate sensitivity (SSSRS) and the SRSW for strain rate jump tests can be calculated using the following equations $[12,45]$ :

$m_{i}=\frac{\ln \left(\sigma_{i} / \sigma_{1}\right)}{\ln \left(\dot{\varepsilon}_{2} / \dot{\varepsilon}_{1}\right)}, m_{s s}=\frac{\ln \left(\sigma_{2} / \sigma_{1}\right)}{\ln \left(\dot{\varepsilon}_{2} / \dot{\varepsilon}_{1}\right)}, m_{w}=m_{s s}-m_{i}$

where $\sigma_{i}$ is the instantaneous true stress, $\sigma_{1}$ and $\sigma_{2}$ are the extrapolated steady-state true stress levels before and after the strain rate jump, $\varepsilon_{1}$ and $\varepsilon_{2}$ are the strain rates before and after the strain rate jump.

Then, the ISRS, SSSRS and SRSW as a function of applied true strain are plotted in Fig. 7b. It is well know that the ISRS provides the information on the response to a strain rate change for fixed micro- structure and temperature. It is clearly shown that the ISRS has a positive value, and this is also due to the thermally-activated nature of dislocation nucleation and propagation [17-21]. However, the SSSRS and SRSW are found to have negative values, this indicates that the microstructure evolution after strain rate change has strong influence on the flow behaviors. Moreover, these negative values of SSSRS and SRSW are also associated with the appearance and the disappearance of PLC bands.

As shown in Fig. 3a, the critical strain for onset of PLC bands increases with increasing applied strain rates. For example, the appearance of PLC bands starts at about $2 \%$ of applied true strain for strain rate of $3.8 \times 10^{-4} / \mathrm{s}$, at about $5 \%$ of applied true strain for strain rate of $2.5 \times 10^{-3} / \mathrm{s}$ and at about $21 \%$ of applied true strain for strain rate of $1.3 \times 10^{-2} / \mathrm{s}$. Fig. 8a shows the true strain as a function of time for both upward jump test (from $2.5 \times 10^{-3} / \mathrm{s}$ to $1.3 \times 10^{-2} / \mathrm{s}$ ) and downward jump test (from $1.3 \times 10^{-2} / \mathrm{s}$ to $2.5 \times 10^{-3} / \mathrm{s}$ ) at the true strain range of $7-17 \%$, and the corresponding strain contours at various true strains are also provided to illustrate the effects of the deformation and microstructure histories on the appearance/disappearance of PLC bands. At the true strain range of 7-17\%, PLC bands should occur at the strain rate of $2.5 \times 10^{-3} / \mathrm{s}$, while should not show up at the strain rate of $1.3 \times 10^{-2} / \mathrm{s}$ for continuous uniaxial tensile experiments. When the strain rate jumps from $2.5 \times 10^{-3} / \mathrm{s}$ to $1.3 \times 10^{-2} / \mathrm{s}$ at the applied true strain of about $10 \%$, the PLC bands do not vanish right away while last for a strain duration of about $3 \%$ before complete disappearance. When the strain rate jumps from $1.3 \times 10^{-2} / \mathrm{s}$ back to $2.5 \times 10^{-3} / \mathrm{s}$ at the applied true strain of about $15 \%$, the PLC bands do not occur right away while persist for a strain duration of about $2 \%$ before complete appearance. These observations clearly indicate that there is a lag 

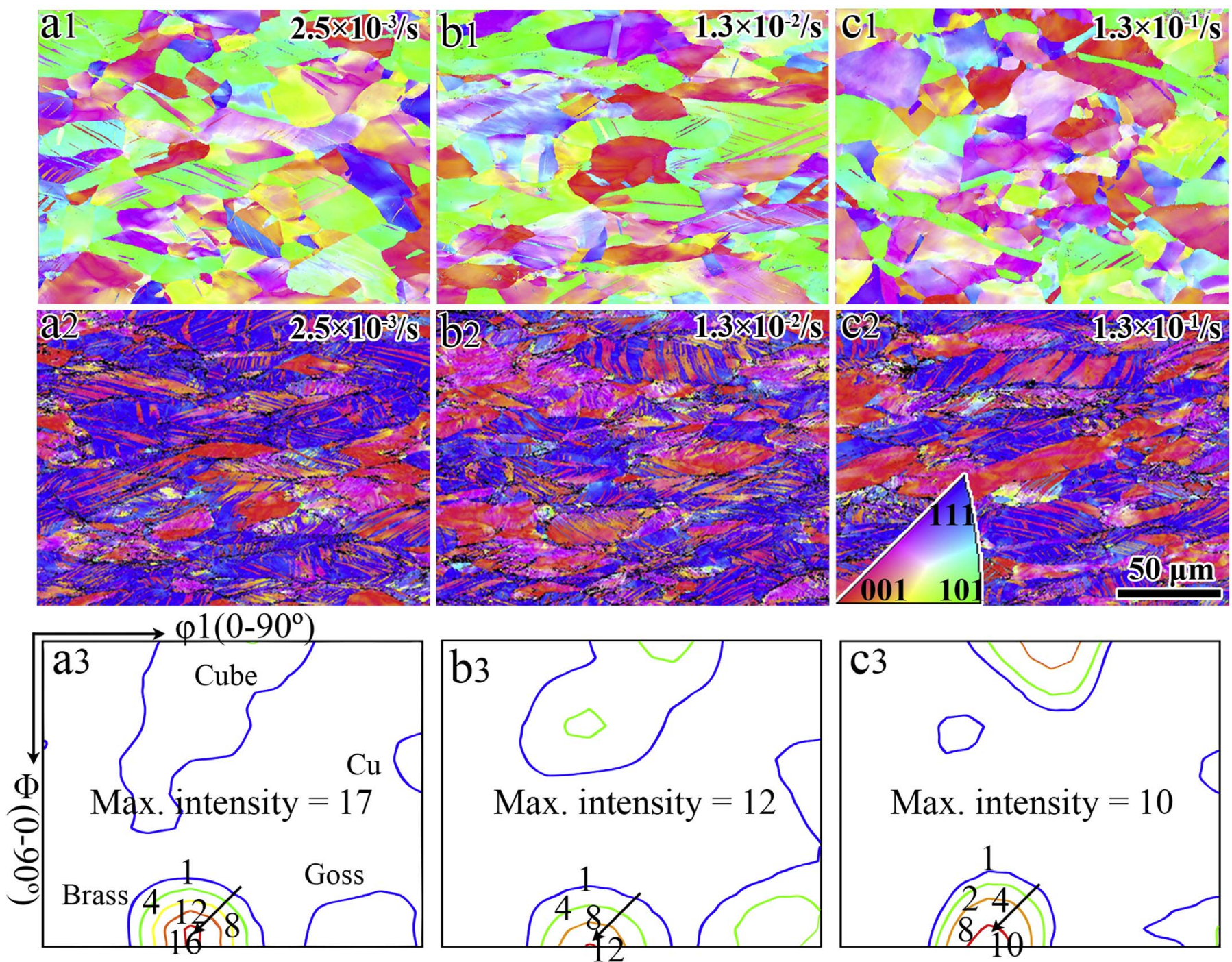

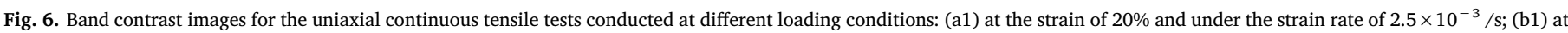

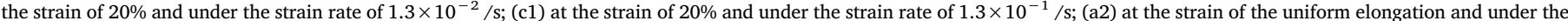

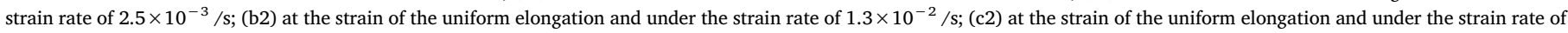

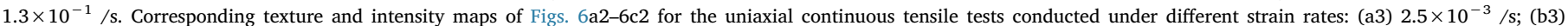
$1.3 \times 10^{-2} / \mathrm{s}$; (c3) $1.3 \times 10^{-1} / \mathrm{s}$.
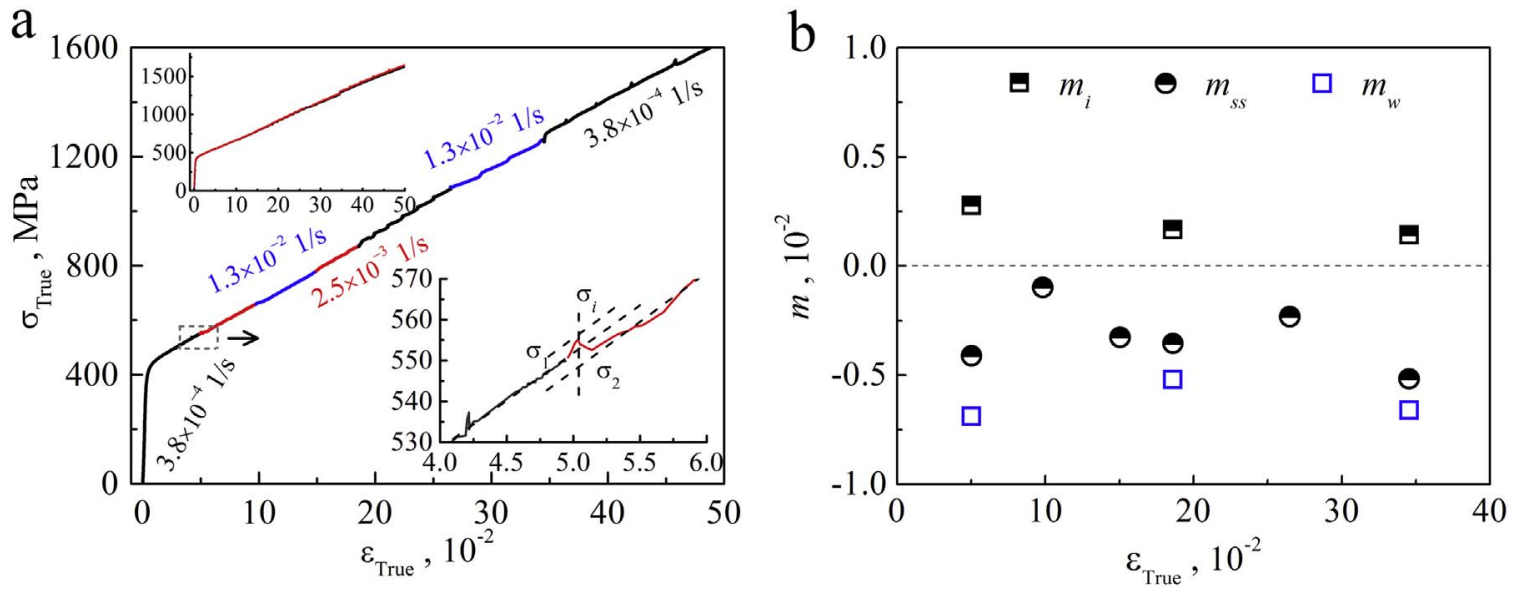

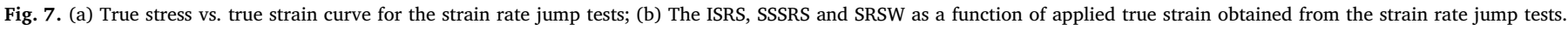



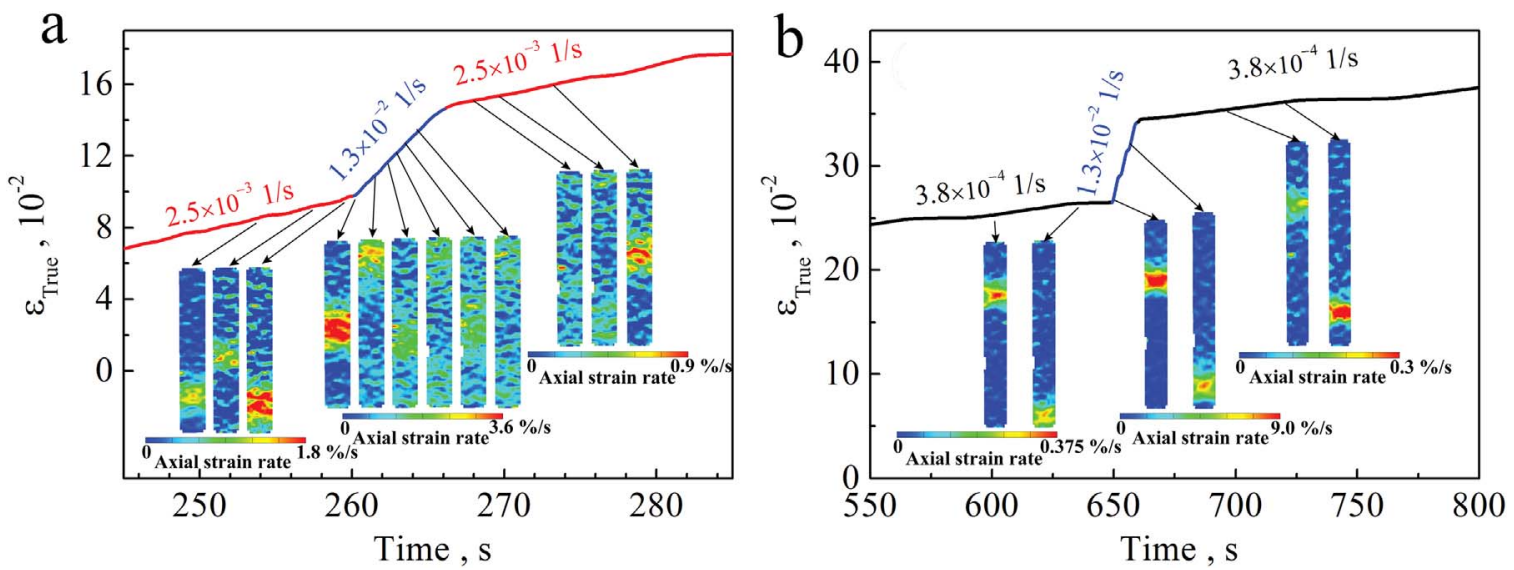

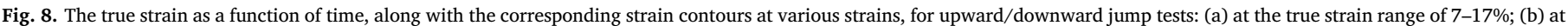
the true strain range of $25-37 \%$.

effect for the appearance/disappearance of PLC bands during the strain rate jump tests, and the appearance/disappearance of PLC bands is highly dependent on the deformation and microstructure evolution histories before the strain rate jump. Fig. 8b shows the true strain as a function of time for both upward jump test (from $3.8 \times 10^{-4} / \mathrm{s}$ to $1.3 \times 10^{-2} / \mathrm{s}$ ) and downward jump test (from $1.3 \times 10^{-2} / \mathrm{s}$ to $3.8 \times 10^{-4} / \mathrm{s}$ ) at the true strain range of $28-45 \%$, and the corresponding strain contours at various strains are also provided. As we know from Fig. 3a, PLC bands should occur at all strain rates at the true strain range of $25-37 \%$ for continuous uniaxial tensile experiments. As shown in Fig. 8b, the PLC bands are always observed during the upward/ downward jump tests for the true strain range of $25-37 \%$, this is consistent with the fact that the deformation and microstructure evolution histories before the true strain of $25 \%$ should provide continuous appearance of PLC bands at any strain rates. These observations in strain rate jump tests further indicate that the negative SRSW is related to the microstructure evolution at various strain rates, such as the propensity of DTs.

\section{Conclusions}

In the present study, the correlation between SRS and characteristics of PLC bands, and the microstructure evolution effect on the flow behaviors have been investigated for a TWIP steel using uniaxial tensile test coupled with DIC method. The following conclusions can be drawn:

(1) The TWIP steel exhibits a negative overall SRS and a negative SRSW. The critical strain for onset of PLC bands is observed to increase with increasing strain rate and the height of the serration behaviors is found to be lower at higher strain rate. These observations indicate that DSA effect is suppressed with increasing strain rate. It is also shown that the strain concentration within PLC band is more severe at higher strain rate. The restriction of DSA effect and the higher strain concentration in the deformation band at higher strain rate result in a lower strain hardening capability and negative values for overall SRS and SRSW.

(2) The formation of DTs is observed to be suppressed at higher strain rate, which can be attributed to the adiabatic heating in the more severely concentrated PLC bands and the restriction of DSA effect by the reduced time for locking at higher strain rate.

(3) The appearance/disappearance of PLC band in strain-rate jump tests is observed to be highly dependent on the deformation and microstructure evolution histories, which further indicates that the overall SRS and SRSW are microstructure dependent parameters for this TWIP steel. The present finding should provide insights for better understanding the deformation physics of the TWIP steel.

\section{Acknowledgements}

This work was financially supported by the National Natural Science Foundation of China (NSFC) under Grant nos. 11472286, 11572328 and 11672313, the National Key Basic Research Program of China under Grant nos. 2012CB932203 and 2012CB937500, and the Strategic Priority Research Program of the Chinese Academy of Sciences under Grant no. XDB22040503.

\section{References}

[1] M.X. Huang, O. Bouaziz, D. Barbier, S. Allain, Modelling the effect of carbon on deformation behaviour of twinning induced plasticity steels, J. Mater. Sci. 46 (2011) 7410-7414.

[2] B. Qin, H. Bhadeshia, Plastic strain due to twinning in austenitic TWIP steels, Mater. Sci. Technol. 24 (2008) 969-973.

[3] J.-K. Kim, L. Chen, H.-S. Kim, S.-K. Kim, Y. Estrin, B.C. De Cooman, On the tensile behavior of high-manganese twinning-induced plasticity steel, Metall. Mater. Trans. A 40 (2009) 3147-3158.

[4] O. Bouaziz, S. Allain, C.P. Scott, P. Cugy, D. Barbier, High manganese austenitic twinning induced plasticity steels: a review of the microstructure properties relationships, Curr. Opin. Solid St. M. 15 (2011) 141-168.

[5] O. Bouaziz, S. Allain, C. Scott, Effect of grain and twin boundaries on the hardening mechanisms of twinning-induced plasticity steels, Scr. Mater. 58 (2008) 484-487.

[6] J.G. Sevillano, An alternative model for the strain hardening of FCC alloys that twin, validated for twinning-induced plasticity steel, Scr. Mater. 60 (2009) 336-339.

[7] O. Bouaziz, Strain-hardening of twinning-induced plasticity steels, Scr. Mater. 66 (2012) 982-985.

[8] J.G. Sevillano, F.D.L. Cuevas, Internal stresses and the mechanism of work hardening in twinning-induced plasticity steels, Scr. Mater. 66 (2012) 978-981.

[9] I. Gutierrez-Urrutia, J.A.D. Valle, S. Zaefferer, D. Raabe, Study of internal stresses in a TWIP steel analyzing transient and permanent softening during reverse shear tests, J. Mater. Sci. 45 (2010) 6604-6610.

[10] Y.F. Shen, N. Jia, R.D.K. Misra, L. Zuo, Softening behavior by excessive twinning and adiabatic heating at high strain rate in a Fe-20Mn-0.6C TWIP steel, Acta Mater. 103 (2016) 229-242.

[11] D. Canadinc, C. Efstathiou, H. Sehitoglu, On the negative strain rate sensitivity of Hadfield steel, Scr. Mater. 59 (2008) 1103-1106.

[12] A. Bintu, G. Vincze, C.R. Picu, A.B. Lopes, J.J. Grácio, F. Barlat, Strain hardening rate sensitivity and strain rate sensitivity in TWIP steels, Mater. Sci. Eng. A 629 (2015) 54-59.

[13] Z.Y. Liang, W. Huang, M.X. Huang, Suppression of dislocation at high strain rate deformation in a twinning-induced plasticity steel, Mater. Sci. Eng. A 628 (2015) 84-88.

[14] Z.Y. Liang, X. Wang, W. Huang, M.X. Huang, Strain rate sensitivity and evolution of dislocations and twins in a twinning-induced plasticity steel, Acta Mater. 88 (2015) $170-179$.

[15] H.K. Yang, Y.Z. Tian, Z.J. Zhang, Z.F. Zhang, Different strain rate sensitivities between Fe-22Mn-0.6C and Fe-30Mn-3Si-3Al twinning-induced plasticity steels, Mater. Sci. Eng. A 655 (2016) 251-255.

[16] L. Chen, H.-S. Kim, S.-K. Kim, B.C. De Cooman, Localized deformation due to Portevin-LeChatelier effect in 18Mn-0.6C TWIP austenitic steel, ISIJ Int. 47 (2007) 1804-1812.

[17] S. Curtze, V.T. Kuokkala, Dependence of tensile deformation behavior of TWIP steels on stacking fault energy, temperature and strain rate, Acta Mater. 58 (2010) 5129-5141.

[18] K.M. Rahman, V.A. Vorontsov, D. Dye, The dynamic behaviour of a twinning 
induced plasticity steel, Mater. Sci. Eng. A 589 (2014) 252-261.

[19] S. Xu, D. Ruan, J.H. Beynon, Y. Rong, Dynamic tensile behaviour of TWIP steel under intermediate strain rate loading, Mater. Sci. Eng. A 573 (2013) 132-140.

[20] O. Grässel, L. Krüger, G. Frommeyer, L.W. Meyer, Dynamic tensile behaviour of TWIP steel under intermediate strain rate loading, Int. J. Plast. 16 (2000) 1391-1409.

[21] J.E. Jin, Y.K. Lee, Effects of $\mathrm{Al}$ on microstructure and tensile properties of C-bearing high Mn TWIP steel, Acta Mater. 60 (2012) 1680-1688.

[22] S. Allain, O. Bouaziz, J.P. Chateau, Thermally activated dislocation dynamics in austenitic FeMnC steels at low homologous temperature, Scr. Mater. 62 (2010) 500-503.

[23] N. Ranc, D. Wanger, Some aspects of Portevin-Le Chatelier plastic instabilities investigated by infrared pyrometry, Mater. Sci. Eng. A 394 (2005) 87-95.

[24] N. Ranc, D. Wanger, Experimental study by pyrometry of Portevin-Le Châtelier plastic instabilities-Type A to type B transition, Mater. Sci. Eng. A 474 (2008) $188-196$.

[25] H. Louche, P. Vacher, R. Arrieux, Thermal observations associated with the Portevin-Le Châtelier effect in an Al-Mg alloy, Mater. Sci. Eng. A 404 (2005) $188-196$.

[26] H. Ait-Amokhtar, C. Fressengeas, S. Boudrahem, The dynamics of Portevin-Le Chatelier bands in an Al-Mg alloy from infrared thermography, Mater. Sci. Eng. A 488 (2008) 540-546.

[27] T.A. Lebedkina, M.A. Lebyodkin, J.-Ph Chateau, A. Jacques, S. Allain, On the mechanism of unstable plastic flow in an austenitic FeMnC TWIP steel, Mater. Sci. Eng. A 519 (2009) 147-154.

[28] R. Shabadi, S. Kumar, H.J. Roven, E.S. Dwarakadasa, Effect of specimen condition, orientation and alloy composition on PLC band parameters, Mater. Sci. Eng. A 382 (2004) 203-208.

[29] H. Ait-Amokhtar, P. Vacher, S. Boudrahem, Kinematics fields and spatial activity of Portevin-Le Chatelier bands using the digital image correlation method, Acta Mater. 54 (2006) 4365-4371.

[30] H. Halim, D.S. Wilkinson, M. Niewczas, The Portevin-Le Chatelier (PLC) effect and shear band formation in an AA5754 alloy, Acta Mater. 55 (2007) 4151-4160.

[31] A. Benallal, T. Berstad, T. Børvik, O.S. Hopperstad, I. Koutiri, R. Nogueira de Codes, An experimental and numerical investigation of the behaviour of AA5083 aluminium alloy in presence of the Portevin-Le Chatelier effect, Int. J. Plast. 24 (2008) 1916-1945.
[32] S. Hong, S.Y. Shin, J. Lee, D.-H. Ahn, H.S. Kim, S.-K. Kim, K.-G. Chin, S. Lee, Serration phenomena occurring during tensile tests of three high-manganese twinning-induced plasticity (TWIP) steels, Metall. Mater. Trans. A 45 (2014) 633-645.

[33] K. Renard, S. Ryelandt, P.J. Jacques, Characterisation of the Portevin-Le Châtelier effect affecting an austenitic TWIP steel based on digital image correlation, Mater. Sci. Eng. A 527 (2010) 2969-2977.

[34] J.Y. Min, J.P. Lin, B. Sun, Effect of strain rate on spatio-temporal behavior of Portevin-Le Châtelier bands in a twinning induced plasticity steel, Mech. Mater. 68 (2014) 164-175.

[35] L.J. Cuddy, W.C. Leslie, Some aspects of serrated yielding in substitutional solid solutions of iron, Acta Metall. Mater. 20 (1972) 1157-1167.

[36] P. Pink, A. Grinberg, Serrated flow in a ferritic stainless steel, Mater. Sci. Eng. 51 (1981) 1-8.

[37] R.G. Xiong, R.Y. Fu, Y. Su, Q. Li, X.C. Wei, L. Li, Tensile properties of TWIP steel at high strain rate, J. Iron Res. Int. 16 (2009) 81-86.

[38] J.R. Klepaczko, C.Y. Chiem, On rate sensitivity of fcc metals, instantaneous rate sensitivity and rate sensitivity of strain hardening, J. Mech. Phys. Solids 34 (1986) 29-54.

[39] G.T. Gray, High-strain-rate deformation: mechanical behavior and deformation substructures induced, Annu. Rev. Mater. Res. 42 (2012) 285-303.

[40] R.W. Armstrong, S.M. Walley, High strain rate properties of metals and alloys, Int. Mater. Rev. 53 (2008) 105-128.

[41] T. Das, R. Saha, S. Bera, K. Dahmen, M. Ghosh, A. Haldar, W. Bleck, S.G. Chowdhury, Effect of high tensile strain rate on the evolution of microstructure in Fe-Mn-C-Al twinning-induced plasticity (TWIP) steel, Metall. Mater. Trans. A 46 (2014) 6-11.

[42] L.P. Kubin, Y. Estrin, Evolution of dislocation densities and the critical conditions for the Portevin-Le Châtelier effect, Acta Metall. Mater. 38 (1990) 697-708.

[43] A.H. Cottrell, LXXXVI. A note on the Portevin-Le Châtelier effect, Philos. Mag. 44 (1953) 829-832.

[44] M.A. Meyers, A. Mishra, D.J. Benson, Mechanical properties of nanocrystalline materials, Prog. Mater. Sci. 51 (2006) 427-556.

[45] S. Venkadesan, P. Rodriguez, K.A. Padmannabhan, P.V. Sivaprasad, C. Phaniraj, Flow transients during strain rate jump tests in a titanium-modified austenitic stainless steel, Mater. Sci. Eng. A 154A (1992) 69-74. 